\title{
THE ANNUAL MEETING IN PITTSBURGH
}

The forty-first Annual Meeting of the American Mathematical Society was held in Pittsburgh, Pennsylvania, from Thursday to Monday, December 27-31, 1934. The University of Pittsburgh and the Carnegie Institute of Technology acted as hosts. The scientific sessions of the Society were held in the Administration Building of the Carnegie Institute of Technology, while the informal New Year's Eve Party was held in the new Cathedral of Learning of the University of Pittsburgh. The arrangements made by the local committee were excellent, and the meeting proved an extremely interesting and pleasant one. At the session on Monday morning, on motion of Professor R. E. Langer, the Society passed a vote of thanks to the local committee and the inviting institutions for their generous hospitality.

As there was no quorum present at the meeting of the Board of Trustees, which had been called for Thursday, December 27, adjournment was taken and a postponed meeting was held in New York on Wednesday evening, January 2. The Council held a meeting on Thursday evening at 7:30 P.M.

The scientific meetings were opened with a general session on Thursday morning. On Thursday afternoon the Society met in three sections, one devoted to Analysis, the second to Algebra and Geometry, and the third to Mathematical Statistics and Applied Mathematics. On Friday morning there were two sectional meetings, one for Analysis and Topology and the other for Algebra.

At a general session on Friday afternoon, Professor A. B. Coble delivered his retiring address as President of the Society. His subject was The geometry of the Weddle manifold $W_{p}$. Later in the afternoon Professor Albert Einstein of the Institute for Advanced Study delivered the eleventh Josiah Willard Gibbs Lecture, entitled $A n$ elementary proof of the theorem concerning the equivalence of mass and energy. Both of these addresses will appear in early numbers of the Bulletin.

On Friday evening there was a joint session of the American Mathematical Society, Sections A and K of the American 
Association for the Advancement of Science, the Mathematical Association of America, and the Econometric Society. A symposium was held on The Nature and Limitations of Statistical Proof. Professor E. B. Wilson spoke on What is a proof?, Professor C. F. Roos on What do time series correlation coefficients show?, Professor H. T. Davis on Statistical proofs of periodicity in economic series, and Mr. Max Sasuly on Practical difficulties in proving statistical relationships. Mr. Carl Snyder, Vice-President of Section K, presided.

A general session was held on Saturday morning. The afternoon was devoted to a symposium on Group Theory and Quantum Mechanics. This was a joint session of the Society with the American Physical Society. Professor E. P. Wigner spoke on Symmetry relations in various physical problems, Professor J. H. Van Vleck on Some applications of group theory to nonrelativistic problems, and Professor Gregory Breit on Some applications of group theory to Dirac's relativistic theory. Professor J. von Neumann, who was to have spoken on Representations and ray representations in quantum mechanics, was unfortunately unable to be present due to illness. Professor H. P. Robertson presided.

On Monday morning there was a joint meeting with the Mathematical Association of America and Section A of the American Association for the Advancement of Science. Professor C. N. Moore delivered his retiring address as Vice-President of Section A. His subject was Mathematics and science. Professor Arnold Dresden also gave his retiring address as President of the Mathematical Association, speaking on the subject $A$ program for mathematics. Professor H. L. Rietz presided at this session.

The banquet of the mathematical organizations was held on Saturday evening in the Georgian Room of the Hotel Webster Hall. About two hundred and ninety persons attended. Professor Dunham Jackson acted as toastmaster and he called on Professors G. D. Birkhoff, L. L. Dines, and Solomon Lefschetz.

The Annual Business Meeting of the Society was held on Friday afternoon. Dr. A. B. Brown, Dr. J. L. Doob, Dr. J. S. Frame, and Professor J. B. Rosenbach were appointed tellers for the annual election. It was reported that 190 ballots had been cast and that the following officers had been elected: 
President, Professor Solomon Lefschetz.

Vice-President, Professor Harry Bateman.

Associate Secretary, Professor J. R. Kline.

Member of the Editorial Committee of the Bulletin, Professor W. R. Longley.

Member of the Editorial Committee of the Transactions, Professor J. D. Tamarkin.

Member of the Editorial Committee of the Colloquium Publications, Professor R. L. Moore.

Members of the Board of Trustees, Professor W. B. Fite, Dr. Robert Henderson, Professors W. R. Longley and G. W. Mullins, and Dean R. G. D. Richardson.

Members of the Council, Professors A. A. Albert, Harold Hotelling, R. E. Langer, D. V. Widder, and R. L. Wilder.

The following eleven institutions of learning and mathematical groups were elected to institutional membership in the Society:

Amherst College;

Columbia University;

Department of Mathematics, University of Nebraska;

Department of Mathematics, Wellesley College;

Division of Mathematics, Harvard University;

Duke University;

McGill University;

Members of Department of Mathematics, College of the City of New York;

Smith College;

Tulane University;

Wesleyan University.

Announcement was made of the election of the following persons to membership in the Society:

Mr. Gilbert F. Boeker, College of the City of New York;

Dr. Josephine Hughes Chanler, University of Illinois;

Professor Richard Courant, New York University;

Major Allen Parker Cowgill (retired), Lincoln, Nebraska;

Miss Carolyn Eisele, Hunter College;

Professor Emil Erno Heimann, East Central State Teachers College, Ada, Oklahoma;

Mr. Fritz Herzog, New York City;

Miss Evelyn M. Hull, New York City;

Dr. John C. Knipp, University of Pittsburgh;

Professor Emmy Noether, Bryn Mawr College;

Professor Ruth M. Peters, Judson College, Marion, Alabama;

Professor Hans A. Rademacher, University of Pennsylvania; 
Mr. Norman F. Ramsey, Jr., Columbia University;

Professor Robert F. Rinehart, Ashland College, Ashland, Ohio;

Sister Rose M. Cook, Loretto Heights College, Loretto, Colorado;

Professor Gabriel Szegö, Washington University;

Mr. Charles Brown Tompkins, Ann Arbor, Michigan;

Professor Marshal Henry Tyler, Rhode Island State College;

Dr. Yun Chiao Yeh, Shanghai, China.

As nominee of the Mathematical Association of America: Professor B. F. Finkel.

As nominee of Yale University: Dr. Max Zorn, Yale University.

As nominee of Wellesley College: Miss Melita A. Holly, Thurston School, Pittsburgh, Pennsylvania.

The ordinary membership in the Society is now 1782, including 49 nominees of institutional members and 81 life members. There are also 24 institutional members. The total attendance of members at all meetings in 1934 was 916 ; the number of papers read was 343 ; the number of members attending at least one meeting was 619 .

The reports of the Treasurer and of the auditors (Professors B. P. Gill and H. W. Reddick, and Mr. J. J. Tanzola) showed a balance of $\$ 4763.01$, exclusive of the balances in the Bulletin, Transactions, Colloquium, Journal, Library, Sinking Fund, and special funds. The Society's Endowment Fund, invested in securities of value $\$ 72,568.26$ (as amortized March, 1934), yielded in 1934 a net income of $\$ 2955.33$; institutional memberships for the year amounted to $\$ 1365$. The amount received from sales of the Society's publications was $\$ 9022.49$; this does not include receipts from Bliss's Algebraic Functions, which have been transmitted to the Revolving Book Fund of the National Research Council. During the year special contributions were received to the amount of $\$ 1020.64$. The trustees adopted a budget for 1935 showing estimated expenditures and receipts as $\$ 41,926.25$ and $\$ 47,495.05$, respectively. The Librarian reported that the Library of the Society now contains 8431 volumes.

Associate Secretary Ingraham reported that encouraging progress had been made up to date in the campaign to stabilize the Society's finances.

The following appointments were announced: as representative on the National Research Council to succeed Professor A. B. Coble, Professor J. H. Van Vleck; as representatives on the 
Council of the American Association for the Advancement of Science for 1935, Professors M. H. Ingraham and C. N. Moore; as nominating committee, Professors J. L. Walsh (chairman), E. T. Bell, L. P. Eisenhart, A. J. Kempner, and E. P. Lane; as committee on arrangements for the summer meeting at Ann Arbor, Professors T. H. Hildebrandt (chairman), W. B. Ford, V. G. Grove, M. H. Ingraham, and G. Y. Rainich; as committee on arrangements for the annual meeting at St. Louis, Professors W. H. Roever (chairman), J. E. Case, M. H. Ingraham, and P. R. Rider, and Dr. W. O. Pennell; as committee on Josiah Willard Gibbs Lecturer for 1935 and 1936, Professors G. C. Evans (chairman), H. W. March, and J. D. Tamarkin; as committee on arrangements for the Thanksgiving meeting at the University of Kentucky, Professors P. P. Boyd (chairman), L. W. Cohen, H. H. Downing, C. G. Latimer, F. E. LeStourgeon.

It was reported that the Annual Meeting of the Society for 1935 would be held in St. Louis in connection with the meetings of the American Association for the Advancement of Science and that a meeting of the Society would be held at the University of Kentucky during the Thanksgiving recess next fall. The Council accepted the kind invitation of Harvard University to hold the Summer Meeting in 1936 at that institution. This will be the occasion of the tercentenary celebration of the founding of Harvard University. An invitation from George Washington University to hold the Annual Meeting at Washington in 1936 in connection with the meetings of the American Association for the Advancement of Science was received with thanks to the inviting institution.

It was reported that Professor E. W. Chittenden had accepted the invitation of the Council to give the Cambridge Colloquium in 1936. Upon recommendation of the Committee on the Visiting Lectureship of the Society, the Council voted to appoint Mr. T. Vijayaraghavan of the University of Dacca, Bengal, India, to this lectureship for 1936.

Through the courtesy of the ladies of the Departments of Mathematics of the University of Pittsburgh and the Carnegie Institute of Technology, tea was served to the visiting mathematicians and their guests on Thursday afternoon in the Faculty Room of the Carnegie Institute of Technology. On New Year's Eve the group was the guest of the local mathematicians at a delightful informal party. 
The attendance included the following two hundred sixty-two members:

C. R. Adams, R. P. Agnew, E. S. Akeley, O. P. Akers, N. L. Anderson, R. C. Archibald, B. M. Armstrong, C. S. Atchison, W. L. Ayres, R. W. Babcock, R. P. Bailey, S. F. Barber, I. A. Barnett, S. R. Benedict, A. A. Bennett, William Betz, H. R. Beveridge, G. D. Birkhoff, A. H. Black, H. L. Black, Henry Blumberg, Salomon Bochner, Paul Boeder, J. W. Bower, M. G. Boyce, Richard Brauer, Gregory Breit, W. C. Brenke, R. W. Brink, H. W. Brinkmann, A. B. Brown, G. S. Bruton, H. E. Buchanan, C. T. Bumer, R. S. Burington, Keivin Burns, W. E. Byrne, S. S. Cairns, W. D. Cairns, Helen Calkins, R. H. Cameron, I. S. Carroll, G. G. Chambers, L. H. Chambers, R. V. Churchill, E. H. Clarke, W. S. Clay tor, A. B. Coble, L. W. Cohen, R. C. Colwell, E. G. H. Comfort, T. F. Cope, A. H. Copeland, L. P. Copeland, Richard Courant, A. T. Craig, C. M. Cramlet, M. M. Culver, C. H. Currier, H. B. Curry, D. R. Curtiss, J. H. Curtiss, E. H. Cutler, H. T. Davis, L. A. V. DeCleene, L. L. Dines, P. S. Donchian, J. L. Doob, Arnold Dresden, J. C. Durand, W. H. Durfee, P. S. Dwyer, M. C. Eide, G. W. Evans, H. P. Evans, H. S. Everett, B. F. Finkel, C. H. Fischer, M. M. Flood, F. A. Foraker, J. S. Frame, A. H. Frink, Orrin Frink, J. J. Gergen, F. J. Gerst, D. C. Gillespie, J. B. Glasgow, Michael Goldberg, F. L. Griffin, L. W. Griffiths, V. G. Grove, B. L. Hagen, E. H. Hanson, W. L. Hart, M. L. Hartung, J. O. Hassler, Alan Hazeltine, E. R. Hedrick, D. M. Hickey, H. C. Hicks, T. H. Hildebrandt, D. L. Holl, T. R. Hollcroft, C. M. Huber, E. M. Hull, Ralph Hull, W. A. Hurwitz, C. A. Hutchinson, M. H. Ingraham, Dunham Jackson, R. L. Jeffery, R. P. Johnson, H. S. Kaltenborn, E. R. van Kampen, D. E. Kearney, H. J. Kersten, S. H. Kimball, J. R. Kline, P. A. Knedler, E. E. Knight, J. C. Knipp, W. D. Lambert, K. W. Lamson, R. E. Langer, G. A. Larew, C. G. Latimer, V. V. Latshaw, Solomon Lefschetz, D. D. Leib, Jack Levine, D. C. Lewis, F. P. Lewis, Marie Litzinger, Dorothy McCoy, N. H. McCoy, J. V. McKelvey, E. J. McShane, L. A. MacColl, C. C. MacDuffee, Saunders MacLane, H. F. MacNeish, Morris Marden, A. E. Meder, D. C. Miller, W. I. Miller, U. G. Mitchell, E. C. Molina, Deane Montgomery, C. N. Moore, T. W. Moore, J. C. Morehead, Max Morris, Richard Morris, W. L. Morris, Marston Morse, Z. I. Mosesson, David Moskovitz, E. J. Moulton, F. D. Murnaghan, J. R. Musselman, S. B. Myers, J. J. Nassau, D. S. Nathan, J. H. Neelley, A. L. Nelson, M. M. Ness, C. O. Oakley, Alta Odoms, F. C. Ogg, Rufus Oldenburger, E. G. Olds, Oystein Ore, E. R. Ott, F. W. Owens, H. B. Owens, F. W. Perkins, H. B. Phillips, H. H. Pixley, Hillel Poritsky, G. B. Price, H. A. Rademacher, Tibor Rad6, G. Y. Rainich, S. M. Rambo, W. C. Randels, L. J. Reed, M. S. Rees, W. D. Reeve, C. N. Reynolds, C. E. Rhodes, D. E. Richmond, H. L. Rietz, N. C. Riggs, H. P. Robertson, Robin Robinson, W. H. Roever, C. F. Roos, J. B. Rosenbach, W. E. Roth, N. E. Rutt, E. A. Saibel, George Sauté, I. J. Schoenberg, H. C. Shaub, C. G. Shover, W. G. Simon, M. E. Sinclair, E. B. Skinner, Joseph Slepian, C. E. Smith, T. L. Smith, W. M. Smith, A. E. Staniland, G. W. Starcher, H. E. Stelson, E. B. Stouffer, W. F. G. Swann, J. L. Synge, Gabriel Szegö, J. D. Tamarkin, J. H. Taylor, J. S. Taylor, M. E. Taylor, M. M. Taylor, C. F. Thomas, J. M. Thomas, Stepan Timoshenko, E. W. Titt, C. C. Torrance, J. I. Tracey, W. J. Trjitzinsky, A. W. Tucker, B. M. Turner, F. E. Ulrich, H. S. 
Vandiver, J. H. Van Vleck, G. W. Walker, R. J. Walker, J. L. Walsh, Morgan Ward, J. H. Weaver, D. W. Weeks, F. M. Weida, M. J. Weiss, C. H. Wheeler, G. T. Whyburn, D. V. Widder, Norbert Wiener, E. P. Wigner, R. L. Wilder, S. S. Wilks, K. P. Williams, C. O. Williamson, E. B. Wilson, E. W. Wilson, Wilfrid Wilson, Aurel Wintner, E. E. Witmer, E. W. Woolard, F. L. Wren, M. M. Young, Max Zorn.

Titles and cross references to abstracts of papers read at the regular sessions follow below. Mr. Laporte was introduced by Professor Rainich, Dr. Kanarik by Professor Tamarkin, Mr. Cannon by Professor Murnaghan, Dr. Knipp by Professor Foraker, Mr. Sewell by Professor Walsh, Mr. Erskine by Professor Murnaghan, Mr. Heins by Professor Franklin, Dr. Robertson by Professor Tamarkin, Dr. Taussky and Professor Rademacher by Professor Kline, and Mr. Petrie by Professor Olds.

The papers were read as follows: papers numbered 1 to 9 in the General Session on Thursday morning, Professor A. B. Coble presiding; papers numbered 10 to 27 in the Section for Algebra on Thursday afternoon, Professor Oystein Ore presiding; papers numbered 28 to 37 in the Section for Analysis on Thursday afternoon, Professor Marston Morse presiding; papers numbered 38 to 45 in the Session on Mathematical Statistics and Applied Mathematics on Thursday afternoon, Professors H. L. Rietz and C. S. Atchison presiding; papers numbered 46 to 67 at the Session for Analysis on Friday morning, Professor J. D. Tamarkin presiding; papers numbered 68 to 75 at the Session on Algebra on Friday morning, Professor C. C. MacDuffee presiding; papers numbered 76 to 87 at the General Session on Saturday morning, Professor Norbert Wiener presiding. Professor Coble presided at the Annual Business Meeting on Friday afternoon and Professor Lefschetz at the General Meeting held immediately thereafter and also at the Willard Gibbs Lecture. Professor H. P. Robertson presided at the Joint Session with the American Physical Society on Saturday afternoon and Professor H. L. Rietz at the Joint Session on Monday morning. The papers whose abstract numbers are followed by the letter $t$ were read by title.

1. On the evaluation of the characteristic numbers of the Laplacean difference equation in rectangular regions, by Professor H. C. Hicks. (Abstract No. 41-1-5.)

2. Pseudominimal hypersurfaces in euclidean four-space, by 
Mr. Otto Laporte and Professor G. Y. Rainich. (Abstract No. 41-1-6.)

3. A set of completely independent postulates for differentiation, by Professor F. W. Perkins. (Abstract No. 41-1-7.)

4. Variation of characteristic parameter values (Eigenwerte), by Dr. Hillel Poritsky. (Abstract No. 41-1-8.)

5. Convergence of sequences of positive linear functional operations, by Mr. R. P. Bailey. (Abstract No. 41-1-9.)

6. Differential equations and expansion theorems in Banach spaces, by Dr. G. B. Price. (Abstract No. 41-1-10.)

7. Linear differential equations with almost periodic coefficients, by Dr. R. H. Cameron (National Research Fellow). (Abstract No. 41-1-11.)

8. Integrability conditions of implicit differential equations, by Professor C. M. Cramlet. (Abstract No. 41-1-60-t.)

9. Interpolation and functions analytic interior to the unit circle, by Professor J. L. Walsh. (Abstract No. 41-1-61-t.)

10. Conditions for factorization in a set closed under a single operation, by Professor Morgan Ward. (Abstract No. 41-1-12.)

11. Some geometric aspects of abstract linear dependence, by Dr. Saunders MacLane. (Abstract No. 41-1-13.)

12. On the equivalence of quadrics in m-affine n-space and its relation to the equivalence of $2 m$-pole networks, by Professor $\mathrm{R}$. S. Burington. (Abstract No. 40-11-340.)

13. On fundamental regions, by Professor M. M. Culver. (Abstract No. 41-1-14.)

14. Fundamental regions in $S_{4}$ for the Hessian group, by Dr. Rosella Kanarik. (Abstract No. 40-11-346.)

15. The web of algebraic surfaces with a basis curve, by Professor T. R. Hollcroft. (Abstract No. 41-1-15.)

16. On semi-vectors and Lorentz transformations, by $\mathrm{Mr}$. E. W. Cannon. (Abstract No. 41-1-16.)

17. Note on the geometric interpretation of the vanishing of a certain projective invariant of two conics, by Dr. Robin Robinson. (Abstract No. 41-1-17.)

18. Relation between the Fregier surface and the evolute, by Dr. J. C. Knipp. (Abstract No. 41-1-18. )

19. A new analogue of the Gauss-Bonnet formula with applications to geodesic triangles, by Dr. I. J. Schoenberg. (Abstract No. 41-1-19.) 
20. Space involutorial transformations of the Geiser and Bertini types, by Dr. L. A. Dye. (Abstract No. 40-11-342-t.)

21. On the mapping of the 24-tuples of the involutorial $G_{24}$ in a plane upon a quadric, by Dr. M. C. Hartley. (Abstract No. 40-11-344-t.)

22. An involutorial line transformation determined by a congruence of twisted cubic curves, by Professor J. M. Clarkson. (Abstract No. 41-1-20-t.)

23. Quaternions and inversive geometry (preliminary report), by Mr. L. B. Robinson. (Abstract No. 41-1-21-t.)

24. Some intrinsic and derived vectors in a Kawaguchi space, by Professor J. L. Synge. (Abstract No. 40-11-351-t.)

25. A problem in recurring series, by Professor Morgan Ward. (Abstract No. 41-1-22-t.)

26. A determination of all possible systems of strict implication, by Professor Morgan Ward. (Abstract No. 41-1-23-t.)

27. The inconsistency of certain formal logics, by Dr. J. B. Rosser and Dr. S. C. Kleene. (Abstract No. 41-1-24-t.)

28. A general theorem on partial differential equations of second order with constant coefficients and some applications, by Professor Richard Courant. (Abstract No. 41-1-25.)

29. Differentiation of sequences, by Professor Orrin Frink, Jr. (Abstract No. 40-11-343.)

30. Laplace integrals and factorial series in the theory of linear differential and linear difference equations, by Professor W. J. Trjitzinsky. (Abstract No. 40-11-352.)

31. An extension of a theorem of Gauss to polygamma functions, by Professor H. T. Davis. (Abstract No. 41-1-26.)

32. Differential equations admitting a conformal group, by Professor Edward Kasner. (Abstract No. 41-1-27-t.)

33. The Jacobi interpolation series on the lemniscate of convergence, by Professor J. L. Walsh and Mr. J. H. Curtiss. (Abstract No. 41-1-28.)

34. Generalized derivatives and approximation by polynomials, by Mr. W. E. Sewell. (Abstract No. 40-11-336.)

35. A mixture theorem concerning non-conservative mechanical systems, by Professor A. H. Copeland. (Abstract No. 41-1-30.)

36. Non-separable metric spaces, by Dr. Deane Montgomery (National Research Fellow). (Abstract No. 41-1-31.) 
37. Functions defined by sequences of integrals, by Professor R. L. Jeffery. (Abstract No. 41-1-62.)

38. Distributions of greatest variates, least variates, and intervals of variation in samples from a rectangular universe, by Professor E. G. Olds. (Abstract No. 40-11-348.)

39. On the frequency function of $x y$, by Professor C. C. Craig. (Abstract No. 41-1-32-t.)

40. Probability of non-independent events, by Mr. G. W. Petrie. (Abstract No. 41-1-33.)

41. A sequence exhibiting correlation due to common elements, by Dr. C. H. Fischer. (Abstract No. 41-1-34.)

42. The theory of statistical estimation, by Dr. J. L. Doob. (Abstract No. 41-1-35.)

43. A comparison of the temperatures in a solid and its scaled model, by Professor R. V. Churchill. (Abstract No. 41-1-36.)

44. The Born-Infeld theory of electromagnetism, by Mr. W. H. Erskine. (Abstract No. 41-1-37.)

45. Dynamics of the homopolar generator, by Mr. W. H. Ingram. (Abstract No. 40-9-307-t.)

46. Transformations on spaces of infinitely many dimensions, by Professor L. W. Cohen. (Abstract No. 41-1-38.)

47. Continuous transformations of finite homogeneous spaces, by Professor Dorothy McCoy. (Abstract No. 41-1-39.)

48. Connections between differential geometry and topology. I: Simply connected surfaces, by Dr. S. B. Myers (National Research Fellow). (Abstract No. 41-1-40.)

49. Concerning $K$-perfect sets, by Professor G. T. Whyburn. (Abstract No. 40-11-353-t.)

50. Triangulation of the manifold of class 1 , by Professor S. S. Cairns. (Abstract No. 40-11-341.)

51. Properties of those spherical maps which may be colored in four colors, by Professor C. N. Reynolds. (Abstract No. 411-41.)

52. Concerning the connectivity of limiting sets, by Professor G. T. Whyburn. (Abstract No. 41-1-42-t.)

53. A theorem on plane continua, by Dr. W. T. Reid. (Abstract No. 41-1-43-t.)

54. An integro-differential boundary problem, by Dr. W. T. Reid. (Abstract No. 41-1-44-t.) 
55. Analytic continuation of solutions of elliptic differential equations, by Dr. H. L. Krall. (Abstract No. 41-1-45-t.)

56. A note on the equation of heat conduction, by Mr. A. E. Heins. (Abstract No. 41-1-46-t.)

57. A basic theorem in the problems of Lagrange and Bolza, by Dr. M. R. Hestenes (National Research Fellow). (Abstract No. 40-11-345-t.)

58. Coincidence of the formulas of mechanical quadratures of Gauss's type and of Tchebycheff's type, by Mr. R. P. Bailey. (Abstract No. 41-1-47-t.)

59. Degree of approximation to continuous functions, by $\mathrm{Mr}$. W. E. Sewell. (Abstract No. 41-1-29-t.)

60. The coefficients of the Laurent series of a univalent function, by Dr. M. S. Robertson (National Research Fellow). (Abstract No. 41-1-48-t.)

61. The radius of univalency of analytic functions, by Dr. M. S. Robertson (National Research Fellow). (Abstract No. 41-1-49-t.)

62. Functions regular and univalent in a sector, by Dr. M. S. Robertson (National Research Fellow). (Abstract No. 41-1-50-t.)

63. Projections in abstract spaces, by Dr. C. C. Torrance. (Abstract No. 41-1-65.)

64. Differential invariant theory of alternating tensors, by Dr. C. M. Cramlet. (Abstract No. 41-1-64.)

65. The closure of Bessel functions, by Professor Norbert Wiener. (Abstract No. 41-1-66.)

66. On complete topological spaces, by Professor John von Neumann. (Abstract No. 41-1-67-t.)

67. Almost periodic functions in groups. II, by Professors Salomon Bochner and John von Neumann. (Abstract No. 41-1-68-t.)

68. Equivalence of multilinear forms singular on one index, by Dr. Rufus Oldenburger. (Abstract No. 41-1-51.)

69. On the rational canonical form of a function of a matrix, by Professor N. H. McCoy. (Abstract No. 40-11-347.)

70. On k-commutative matrices, by Professor W. E. Roth. (Abstract No. 40-11-349.)

71. On the irreducible representations of hyperorthogonal groups (preliminary report), by Dr. J.S. Frame. (Abstract No. 41-1-52.)

72. Fields as class fields of different reference fields, by Dr. Olga Taussky. (Abstract No. 41-1-53.) 
73. Some remarks in the theory of algebraic functions, by Dr. Max Zorn. (Abstract No. 41-1-69.)

74. Hypergroups (preliminary report), by Professor H. S. Wall. (Abstract No. 41-1-70-t.)

75. Cyclotomy and trinomial congruences, by Professor L. E. Dickson. (Abstract No. 41-1-71-t.)

76. Uniform instability and dynamical discontinua, by Professor Marston Morse. (Abstract No. 41-1-54.)

77. Principal null-directions in space-time defined by an electromagnetic field, by Professor J. L. Synge. (Abstract No. 40-11350.)

78. Condition that a harmonic function be a potential of positive mass, by Professor G. C. Evans. (Abstract No. 41-1-55-t.)

79. Convergence factors for series summable by Nörlund means of a certain type, by Professor C. N. Moore. (Abstract No. 411-56.)

80. A new estimate of the number of prime numbers in a real quadratic field, by Professor Hans Rademacher. (Abstract No. 41-1-57.)

81. A classification of generating functions, by Professor D. V. Widder. (Abstract No. 41-1-58.)

82. On normal division algebras of prime degree (preliminary report), by Professor Richard Brauer. (Abstract No. 41-1-59.)

83. A characterization of manifold boundaries in $E_{n}$ dependent only on lower dimensional connectivities of the complement, by Professor R. L. Wilder. (Abstract No. 40-11-354.)

84. A problem concerning orthogonal polynomials, by Professor Gabriel Szegö. (Abstract No. 41-1-72-t.)

85. A representation of the most general positive harmonic function in a bounded domain in three-dimensional euclidean space whose boundary points are conical, by Professor A. J. Maria. (Abstract No. 41-1-73-t.)

86. On the behavior of a harmonic function in the neighborhood of the boundary, by Professor A. J. Maria. (Abstract No. 411-74-t.)

87. On the problem of Pfaff, by Professor C. M. Cramlet. (Abstract No. 41-1-63-t.)

J. R. KLINE, Associate Secretary 